\title{
Higher carbon sequestration potential and stability for deep soil compared to surface soil regardless of nitrogen addition in a subtropical forest
}

\author{
Chang Liao ${ }^{1,2}$, Dong Li ${ }^{1,2,3}$, Lin Huang ${ }^{1,2}$, Pengyun Yue ${ }^{1,2}$, Feng Liu ${ }^{1}$, Qiuxiang Tian ${ }^{\text {Corresp. } 1}$ \\ ${ }^{1}$ Key Laboratory of Aquatic Botany and Watershed Ecology, Wuhan Botanical Garden, Chinese Academy of Sciences, Wuhan, China \\ 2 University of Chinese Academy of Sciences, Beijing, China \\ ${ }^{3}$ College of science, Tibet University, Lasa, China \\ Corresponding Author: Qiuxiang Tian \\ Email address: tianqiuxiang@wbgcas.cn
}

Background. Labile carbon input could stimulate soil organic carbon (SOC) mineralization through priming effect, resulting in soil carbon (C) loss. Meanwhile, labile $\mathrm{C}$ could also be transformed by microorganisms in soil as the processes of new $\mathrm{C}$ sequestration and stabilization. Previous studies showed the magnitude of priming effect could be affected by soil depth and nitrogen (N). However, it remains unknown how the soil depth and $\mathrm{N}$ availability affect the amount and stability of the new sequestrated $\mathrm{C}$, which complicates the prediction of $\mathrm{C}$ dynamics.

Methods. A 20-day incubation experiment was conducted by adding ${ }^{13} \mathrm{C}$ labeled glucose and $\mathrm{NH}_{4} \mathrm{NO}_{3}$ to study the effects of soil depth and nitrogen addition on the net $\mathrm{C}$ sequestration. SOC was fractioned into seven fractions and grouped into three functional $\mathrm{C}$ pools to assess the stabilization of the new sequestrated $\mathrm{C}$.

Results. Our results showed that glucose addition caused positive priming in both soil depths, and $\mathrm{N}$ addition significantly reduced the priming effect. After 20 days of incubation, deep soil had a higher $\mathrm{C}$ sequestration potential ( $48 \%$ glucose-C) than surface soil ( $43 \%$ glucose- $C$ ). The $C$ sequestration potential was not affected by $\mathrm{N}$ addition in both soil depths. Positive net $\mathrm{C}$ sequestration was observed with higher amount of retained glucose-C than that of stimulated mineralized SOC for both soil depths. The distribution of new sequestrated $C$ in the seven fractions was significantly affected by soil depth, but not $\mathrm{N}$ addition. Compared to deep soil, the new $\mathrm{C}$ in surface soil was more distributed in the non-protected $\mathrm{C}$ pool (including water extracted organic $\mathrm{C}$, light fraction and sand fraction) and less distributed in the clay fraction. These results suggested that the new $C$ in deep soil was more stable than that in surface soil. Compared to the native SOC for both soil depths, the new sequestrated $C$ was more distributed in nonprotected C pool and less distributed in biochemically protected C pool (non-hydrolyzable silt and clay fractions). The higher carbon sequestration potential and stability in deep soil suggested that deep soil has a greater role on $\mathrm{C}$ sequestration in forest ecosystems. 
1 Higher carbon sequestration potential and stability for deep soil compared to surface soil regardless of nitrogen addition in a subtropical forest

4 Chang Liao ${ }^{1,2}$, Dong $\mathrm{Li}^{1,2,3}$, Lin Huang ${ }^{1,2}$, Pengyun Yue ${ }^{1,2}$, Feng Liu ${ }^{1}$, Qiuxiang Tian ${ }^{1 *}$

$5 \quad{ }^{1}$ Key Laboratory of Aquatic Botany and Watershed Ecology, Wuhan Botanical Garden, Chinese

6 Academy of Sciences, Wuhan 430074, China

$7 \quad{ }^{2}$ University of Chinese Academy of Sciences, Beijing 100049, China

$8{ }^{3}$ College of Science, Tibet University, Lasa 850000, China

9

$10 *$ Corresponding author:

11 Qiuxiang Tian

12

E-mail addresses: tianqiuxiang@wbgcas.cn 


\section{Abstracts:}

Background. Labile carbon input could stimulate soil organic carbon (SOC) mineralization through priming effect, resulting in soil carbon (C) loss. Meanwhile, labile $\mathrm{C}$ could also be transformed by microorganisms in soil as the processes of new $\mathrm{C}$ sequestration and stabilization. Previous studies showed the magnitude of priming effect could be affected by soil depth and nitrogen $(\mathrm{N})$. However, it remains unknown how the soil depth and $\mathrm{N}$ availability affect the amount and stability of the new sequestrated $\mathrm{C}$, which complicates the prediction of $\mathrm{C}$ dynamics.

Methods. A 20-day incubation experiment was conducted by adding ${ }^{13} \mathrm{C}$ labeled glucose and $\mathrm{NH}_{4} \mathrm{NO}_{3}$ to study the effects of soil depth and nitrogen addition on the net $\mathrm{C}$ sequestration. SOC was fractioned into seven fractions and grouped into three functional $\mathrm{C}$ pools to assess the stabilization of the new sequestrated $\mathrm{C}$.

Results. Our results showed that glucose addition caused positive priming in both soil depths, and $\mathrm{N}$ addition significantly reduced the priming effect. After 20 days of incubation, deep soil had a higher $\mathrm{C}$ sequestration potential ( $48 \%$ glucose-C) than surface soil ( $43 \%$ glucose-C). The $\mathrm{C}$ sequestration potential was not affected by $\mathrm{N}$ addition in both soil depths. Positive net $\mathrm{C}$ sequestration was observed with higher amount of retained glucose- $\mathrm{C}$ than that of stimulated mineralized SOC for both soil depths. The distribution of new sequestrated $\mathrm{C}$ in the seven fractions was significantly affected by soil depth, but not $\mathrm{N}$ addition. Compared to deep soil, the new $\mathrm{C}$ in surface soil was more distributed in the non-protected $\mathrm{C}$ pool (including water extracted organic $\mathrm{C}$, light fraction and sand fraction) and less distributed in the clay fraction. These results suggested that the new $\mathrm{C}$ in deep soil was more stable than that in surface soil. Compared to the native SOC for both soil depths, the new sequestrated $\mathrm{C}$ was more distributed in non-protected $\mathrm{C}$ pool and less distributed in biochemically protected $\mathrm{C}$ pool (non-hydrolyzable 
37 silt and clay fractions). The higher carbon sequestration potential and stability in deep soil suggested that deep soil has a greater role on $\mathrm{C}$ sequestration in forest ecosystems.

Keywords: nitrogen addition; soil depths; soil carbon fractions; soil carbon sequestration; soil carbon stability; net carbon sequestration

\section{Introduction}

Soil organic carbon (SOC) is a major carbon reservoir in the terrestrial ecosystems and its slight change would have a considerable impact on the global carbon (C) balance (Cotrufo et al., 2015). Litter and root exudation provide a large amount of labile substrate to soil microorganisms (Paul, 2016), mediating C cycling in the terrestrial ecosystems (Cheng et al., 2014; Paul, 2016). First, inputs of labile C can greatly enhance native SOC mineralization, which is termed as priming effect (PE) (Blagodatskaya \& Kuzyakov, 2008; Kuzyakov, 2010; Blagodatskaya et al., 2007). Second, part of the added labile C can be retained in the soil to compensate the SOC loss caused by PE (Ohm et al., 2007; Liang \& Balser, 2012; Cotrufo et al., 2013; Cotrufo et al., 2015; Liang et al., 2017). Hence, labile C input studies should consider net C balance between the retained C and the primed C (Griepentrog et al., 2014). Additionally, the primed C was found to be originated from stable SOC (Fontaine et al., 2007; Blagodatskaya et al., 2011; Derrien et al., 2014). If the retained C is less stable than the primed C, the long-term effect of C input on SOC storage remains uncertain. Therefore, it is necessary to investigate how much exogenous $\mathrm{C}$ can be sequestrated in soil and the stabilization of the new sequestrated $\mathrm{C}$ (Powlson et al., 2014; Janzen, 2015). This new knowledge can show new insights into our accurate assessment of the impact of labile $\mathrm{C}$ input on soil $\mathrm{C}$ pool.

Current studies suggested that the new sequestrated $\mathrm{C}$ has faster turnover time and lower 
60 stability (Derrien et al., 2014; van Groenigen et al., 2017). However, the reason underlying the 61 phenomenon was poorly understood. It is necessary to reveal the SOC stabilization mechanism

62 for the accurate evaluation of SOC stability. Soil fractionation analysis is frequently used to 63 study the stabilization mechanisms of SOC by separating SOC into different $\mathrm{C}$ fractions. These 64 SOC fractions correspond to different mean residence times and stabilization mechanisms 65 (Christensen, 1992; Christensen, 2001; Six et al., 2002; von Lützow et al., 2007). Therefore, studying the dynamics of labile $\mathrm{C}$ incorporation into these soil fractions can elucidate the new $\mathrm{C}$ stabilization mechanisms and evaluate its stability.

Deep soil (below $30 \mathrm{~cm}$ ) contains more than half of the total soil C stocks (Rumpel \& Kögel-Knabner, 2011). The response of deep soil to labile C input is thus important to terrestrial C balance. Previously studies generally founded deep soil had a stronger PE than surface soil due to its soil physio-chemical and microbial properties (Tian et al., 2016; Wang et al., 2014b). It's urgent to know how much and how long the exogenous $\mathrm{C}$ can be retained in soil to evaluate the long-term $\mathrm{C}$ sequestration in forest ecosystems.

Soil C cycling under labile $\mathrm{C}$ input can be mediated by nitrogen $(\mathrm{N})$ availability (Chen et al., 2014; Qiu et al., 2016). Many studies mostly found that higher $\mathrm{N}$ availability could reduce soil PE by regulating soil microbial activity and metabolic efficiency (Wang et al., 2014a; Wang et al., 2014b; Chen et al., 2019). The changed microbial properties might further affect exogenous $\mathrm{C}$ mineralization and $\mathrm{C}$ sequestration. Field researches showed $\mathrm{N}$ addition could significantly regulate SOC balance mainly through indirect effects on vegetation C input (Liu et al., 2019). However, the direct impact of $\mathrm{N}$ addition on new $\mathrm{C}$ sequestration was unclear. In order to identify the effects of soil depth and $\mathrm{N}$ availability on the soil $\mathrm{C}$ sequestration potential and the stability of the new sequestrated $C$, surface soil $(0-10 \mathrm{~cm})$ and deep soil $(30-60$ 
83

84

$\mathrm{cm}$ ) from a subtropical forest were incubated for 20 days with the addition of ${ }^{13} \mathrm{C}$ labeled glucose and $\mathrm{NH}_{4} \mathrm{NO}_{3}$. Soil $\mathrm{CO}_{2}$ efflux rates and $\delta^{13} \mathrm{C}$ values were measured during the incubation. SOC was fractioned into seven fractions and collectively divided into three functional pools by a combination of density, particle and chemical methods to elucidate C stability. Previous studies showed that SOC in deep soil was further away from C saturation than that in surface soil, and deep SOC was less decomposable than surface SOC (Stewart et al., 2008; Poirier et al., 2013; Derrien et al., 2014; van Groenigen et al., 2017). Therefore, we hypothesized that the deep soil could retain higher proportion of exogenous $\mathrm{C}$ than surface soil, and the new $\mathrm{C}$ in the deep soil was more stable. We also hypothesized that $\mathrm{N}$ addition could increase the new $\mathrm{C}$ sequestration and stability.

\section{Material and methods}

\subsection{Soil collection}

Soil samples used in this experiment were collected in an evergreen and deciduous broadleaved mixed forest located at Badagongshan National Research Reserve $\left(29^{\circ} 46.04^{\prime} \mathrm{N}, 110^{\circ}\right.$ 5.24' E) in Sangzhi County, Hunan Province. More detailed site description could be seen in Tian et al. (2016).

The soils were collected from two depth intervals: $0-10$ and 30-60 cm (representing the surface soil and deep soil, respectively) through digging a trench. The $10-30 \mathrm{~cm}$ soil included mixed samples from mineral A layer, transition layer, and Bts layer. Therefore, we did not consider this layer in our study. The soils were homogenized and then sieved $(2 \mathrm{~mm})$. The coarse roots and visible residues were picked out during the sieving. Soils were stored below $4{ }^{\circ} \mathrm{C}$ until further incubation. SOC and TN contents were 131.7 and $7.9 \mathrm{mg} \cdot \mathrm{g}^{-1}$ in surface soil, and was 35.7 
106

107

108

109

110

111

112

113

114

115

116

117

118

119

120

121

122

123

124

125

126

127 128

and $2.7 \mathrm{mg} \cdot \mathrm{g}^{-1}$ in deep soil (Table 1). The clay contents were $22.6 \%$ and $39.6 \%$ in surface soil and deep soil, respectively.

\subsection{Experimental design and soil incubation}

The incubation experiment included three treatments: soil without addition (Control), soil with glucose addition $(\mathrm{Glu})$, and soil with combined additions of glucose and $\mathrm{N}(\mathrm{Glu}+\mathrm{N})$ with six replicates. For each soil, the amount of added glucose-C corresponded to $100 \%$ of soil microbial biomass C (MBC) (surface soil, $2061.8 \mu \mathrm{g} \mathrm{C} \mathrm{g}^{-1}$ soil; deep soil, $154.7 \mu \mathrm{g} \mathrm{C} \mathrm{g}^{-1}$ soil).

This quantity has been widely adopted in priming experiments (Li et al., 2017, Chen et al., 2019).

The amount of $\mathrm{N}$ addition corresponded to the $\mathrm{C}$ : $\mathrm{N}=10$ of the added substrate with $\mathrm{NH}_{4} \mathrm{NO}_{3}$ (surface soil, $206.18 \mu \mathrm{g} \mathrm{N} \mathrm{g}^{-1}$; deep soil, $15.47 \mu \mathrm{g} \mathrm{N} \mathrm{g}^{-1}$ soil). The control received the same amount of distilled water. For incubation, about $60 \mathrm{~g}$ soil (equivalent to $30 \mathrm{~g}$ dry soil) for each replicate was placed into an individual $250 \mathrm{~mL}$ Erlenmeyer flask. Soil samples were preincubated at $20^{\circ} \mathrm{C}$ for 5 days in the dark condition. After pre-incubation, each replicate of Glu and $\mathrm{Glu}+\mathrm{N}$ treatments was amended with aliquots of glucose solution (uniformly labeled, $\delta^{13} \mathrm{C}$ $=2000 \%$ ) with or without $\mathrm{N}$ source $\left(\mathrm{NH}_{4} \mathrm{NO}_{3}\right)$. For the control treatment, equivalent distilled $\mathrm{H}_{2} \mathrm{O}(3 \mathrm{~mL})$ was added to the soil samples. Then, soil samples were incubated in dark under the ambient air condition for 20 days. During the incubation, the soil water content was maintained at $65 \%$ water-holding capacity by weighing the flask every 4 days. Soil $\mathrm{CO}_{2}$ efflux rates were measured on days $0,1,2,3,4,7,10,15$ and 20 . After the 20 days incubation, the $\mathrm{CO}_{2}$ efflux rate tended to be constant. Thereafter, destructive samplings were conducted. Three replicates were used to measure the $\mathrm{MBC}$, and the other three replicates were oven dried at $60^{\circ} \mathrm{C}$ to analyze SOC fractions. 
130

131

132

133

134

135

136

137

\subsection{Measurements of $\mathrm{CO}_{2}$ efflux rates}

At each measurement time, three of the replicates were randomly chosen to measure $\mathrm{CO}_{2}$ efflux rates by an infrared gas analyzer (IRGA; EGM-4, PP Systems, USA). Another three replicates of each treatment were chosen to determine $\delta^{13} \mathrm{C}$ of the released $\mathrm{CO}_{2}$ by Carbon isotope analyzer (912-0003, LGR, USA). The detailed procedures could be seen in Tian et al. (2016).

\subsection{Measurement of $M B C$}

MBC was determined by the chloroform fumigation extraction method (Vance et al., 1987). Soil samples were divided into two $10 \mathrm{~g}$ fresh soil. One was fumigated with ethanol-free chloroform for $24 \mathrm{~h}$ followed by extraction with $0.05 \mathrm{~mol} \mathrm{~L}^{-1} \mathrm{~K}_{2} \mathrm{SO}_{4}$ (shaken for $30 \mathrm{~min}$ ) and the other was extracted immediately with $0.05 \mathrm{~mol} \mathrm{~L}^{-1} \mathrm{~K}_{2} \mathrm{SO}_{4}$ (shaken for $30 \mathrm{~min}$ ). The extraction was then determined by Total Organic Carbon Analyzer (Vario TOC, Elemental, Germany). The $\mathrm{MBC}$ (difference in $\mathrm{K}_{2} \mathrm{SO}_{4}$-extractable $\mathrm{C}$ between fumigated and non-fumigated samples) were corrected using universal conversion factors of 0.45 (Garcia-Pausas and Paterson 2011). The extractable $\mathrm{C}$ content for the non-fumigated soil samples was considered as dissolved organic carbon (DOC).

\subsection{SOC fractionation}

Soils were fractionated using a combination of density, particle and chemical protocol, adapted and modified from Denef et al. (2013) and Six et al. (2002) (Fig. S1). Before SOC fractionation, water-extractable organic carbon (WEOC) was extracted by shaking $5 \mathrm{~g}$ of dried 
152 soil $(<2 \mathrm{~mm})$ in $20 \mathrm{~mL}$ of deionized water on a shaker for $2 \mathrm{~h}$. After extraction, the solid residue

153 was separated into light fraction, sand, silt and clay. Briefly, the oven-dried $\left(60^{\circ} \mathrm{C}\right)$ solid residue

154 soil was placed in a $50 \mathrm{~mL}$ centrifuge tube and $25 \mathrm{~mL}$ of NaI solution with a density of $1.85 \mathrm{~g}$

$155 \mathrm{~cm}^{-3}$ were added. Tubes with the soil-NaI mixture were shaken in a shaker table at $300 \mathrm{rpm}$ for 2

$156 \mathrm{~h}$. Then, the samples were centrifuged and the floating light fraction (LF) (LF $\left.<1.85 \mathrm{~g} \mathrm{~cm}^{-3}\right)$ was

157 transferred onto the microfiltration membrane and filtered under vacuum. The remaining heavy

158 fraction was washed with deionized water to remove $\mathrm{NaI}$ and then sieved through a $53 \mu \mathrm{m}$ screen

159 to separate the sand $(>53 \mu \mathrm{m})$ fraction from the silt and clay. Silt and clay fractions were

160 separated through wet centrifugation (127 $\mathrm{g}$ for $7 \mathrm{~min}$ for silt, and $1730 \mathrm{~g}$ for $15 \mathrm{~min}$ for clay,

161 and then further hydrolyzed in $6 \mathrm{~mol} \mathrm{~L}^{-1} \mathrm{HCl}$ at $95^{\circ} \mathrm{C}$ for $16 \mathrm{~h}$. The $\mathrm{C}$ in the suspension and

162 residue were considered as hydrolyzable $\mathrm{C}$ fraction (H-silt, $\mathrm{H}$-clay) and non-hydrolyzable $\mathrm{C}$

163 fraction (NH-silt, NH-clay), respectively.

164 All solid fractions were oven-dried at $60{ }^{\circ} \mathrm{C}$ prior to weighing. $\mathrm{C}$ content and its $\delta^{13} \mathrm{C}$ in the

165 solid fractions were measured on a thermal combustion elemental analyzer (Fisher Flash 2000,

166 Thermo Fisher, USA) interfaced with a stable isotope Mass Spectrometer (Delta V Advantage,

167 Thermo Finigan, Germany). C content in the water solution was determined by TOC (Vario TOC,

168 Elemental, Germany).

169 The $\delta^{13} \mathrm{C}$ of WEOC and DOC was determined by sodium persulfate oxidation to transform

170 the liquid into gas modified by Midwood et al. (2006) and Garcia-Pausas and Paterson (2011).

171 Briefly, $10 \mathrm{~mL}$ water solution was added into a $250 \mathrm{~mL}$ reaction bottle and then $100 \mu \mathrm{L}$ of 1.3

$172 \mathrm{~mol} \mathrm{~L}^{-1}$ phosphoric acid solution was added to remove inorganic $\mathrm{C}$ from the solution. After that,

$173200 \mu \mathrm{L}$ of $1.05 \mathrm{~mol} \mathrm{~L}^{-1}$ sodium persulfate was added. In the blank control, $10 \mathrm{~mL}$ ultrapure water

174 was added, and the other steps were the same. The reaction bottle was then capped and flushed 
175 with $\mathrm{CO}_{2}$-free air. The sample was then heated in a $90^{\circ} \mathrm{C}$ water bath for 30 minutes to promote

176 the oxidation reaction. The gas in the bottle was transferred into airbag to determine the $\mathrm{CO}_{2}$

177 isotope value by Carbon isotope analyzer (912-0003, LGR, USA).

178 The seven fractions were further divided into three functional $\mathrm{C}$ pools based on the supposed

179 relationship between the soil fractions and the stabilization mechanisms: non-protected C pool,

180 chemically protected C pool and biochemically protected pool modified from Six et al. (2002).

181 The constitute of three functional C pools was shown in Fig. S1

\subsection{Calculations}

The soil $\mathrm{CO}_{2}$ efflux rate derived from native $\mathrm{SOC}$ and glucose-C during incubation was calculated in Tian et al. (2016). calculated as follows:

$A R_{\text {primed }}=A R_{\text {SOC (treatment })}-A R_{S O C(\text { control })}$

Relative PE $(\%)=A R_{\text {primed }} / A R_{\text {SOC (control })} \times 100$

where $A R_{\text {primed }}$ is the amount of primed C during the incubation. $A R_{S O C(\text { treatment) }}$ is the soil cumulative released-C in control. to simple isotopic mixing model:

$195 f=\left(\delta^{13} C_{\text {treatment }}-\delta^{13} C_{\text {control }}\right) /\left(\delta^{13} C_{G l u}-\delta^{13} C_{\text {control }}\right)$

196 where the $\delta^{13} C_{\text {treatment }}$ and $\delta^{13} C_{\text {control }}$ were the $\delta^{13} C$ value of each $\mathrm{C}$ fractions in the treatments with

197 glucose addition and control, respectively. $\delta^{13} C_{G l u}$ is the isotopic signature of the glucose C 
198 added to the soil samples. The amounts of new $\mathrm{C}$ in bulk and soil fractions were calculated 199 according to $\mathrm{C}$ content in bulk soil and soil fractions as well as $f$.

200 The sequestration potential for glucose-C (proportion of glucose- $\mathrm{C}$ retained in soil) was 201 calculated as follows:

202

C sequestration potential $(\%)=C_{\text {retained }} / C_{\text {addition }} \times 100$

203 where $C_{\text {retained }}$ is the amount of glucose-C retained (new C) in soil, $C_{\text {addition }}$ is the amount of 204 added glucose.

205 The content of net sequestrated $\mathrm{C}$ was calculated as the difference between $C_{\text {retained }}$ and $A R_{\text {primed }}$. 206 The net $\mathrm{C}$ sequestration potential was calculated as the content of net sequestrated $\mathrm{C}$ per unit of 207 added glucose-C:

Net $C$ sequestration potential $(\%)=\left(C_{\text {retained }}-\mathrm{AR}_{\text {primed }}\right) / C_{\text {addition }} \times 100(5)$

The microbial metabolic quotient $\left(q \mathrm{CO}_{2}\right)$ was calculated as the $\mathrm{CO}_{2}$ efflux rate per unit of MBC on day 20.

\subsection{Statistical analysis}

The differences in $\mathrm{CO}_{2}$ efflux rate, isotope signature of each soil fraction, and $q \mathrm{CO}_{2}$ among soil depth and $\mathrm{N}$ availability on the amount of primed $\mathrm{C}$, the relative magnitude of $\mathrm{PE}$, the amount of retained glucose $\mathrm{C}$, the sequestration potential, the net $\mathrm{C}$ sequestration, and the distribution of new $\mathrm{C}$ in each soil fraction were compared using two-way ANOVA. Tukey's post

218 hoc test was used to identify significant differences at $P<0.05$. The distributions of new $\mathrm{C}$ and native $\mathrm{C}$ in each soil fraction were compared through independent $\mathrm{t}$ test. Principal component analysis (PCA) was used to analyze the distribution of new $\mathrm{C}$ and native $\mathrm{C}$ in soil fractions. 
221 Permutational multivariate analysis of variance (PERMANOVA) with Euclidean distance

222 matrixes was used to evaluate the difference of distribution between new $\mathrm{C}$ and native $\mathrm{C}$ under

223 the two soil depths. Statistical analyses were performed using SPSS version 21.0. The PCA was

224 conducted using the "vegan", "lattice", "permute" packages in R version 3.5.1. The

225 PERMANOVA analysis was performed using Past 3.

226

227 3. Result

228

229

230

231

232

233

234

235

236

237

238

239

240

241

242

243

\subsection{SOC mineralization and glucose-C retention}

Glucose addition increased the $\mathrm{CO}_{2}$ efflux rate (Fig. S2). One part of the increased $\mathrm{CO}_{2}$ efflux was from the added glucose (glucose-derived $\mathrm{CO}_{2}$ ), while the other part was from the native $\mathrm{SOC}$ (native $\mathrm{SOC}$-derived $\mathrm{CO}_{2}$ ). The amount of primed $\mathrm{C}$ and the relative magnitude of PE were significantly affected by soil depth and $\mathrm{N}$ availability, and no interaction effect between soil depth and $\mathrm{N}$ availability was observed (Table 2 and $\mathrm{S} 1$ ). The relative magnitude of PE was higher in deep soil than that in surface soil, and $\mathrm{N}$ addition significantly decreased them in both soil depths.

After 20 days of incubation, the amount of retained glucose- $\mathrm{C}$ and the $\mathrm{C}$ sequestration potential were significantly affected by soil depth, but showed no difference between Glu and $\mathrm{Glu}+\mathrm{N}$ treatments in both soil depths (Table 2). The retained glucose-C was averaged $875.3 \mu \mathrm{g}$ $\mathrm{g}^{-1}$ and $78.3 \mu \mathrm{g} \mathrm{g}^{-1}$ in surface soil and deep soil, respectively (Table 2). Deep soil had significantly higher $\mathrm{C}$ sequestration potential $(49.9 \pm 1.1 \%)$ than surface soil $(43.6 \pm 0.1 \%)$.

The net $\mathrm{C}$ sequestration was quantified by calculating the trade-off between the retained glucose-C and the primed C. At the end of 20 days incubation, the retained glucose-C was higher than the amounts of primed $\mathrm{C}$, resulting in overall positive net $\mathrm{C}$ sequestration for both soil 
244 depths (Table 2). The amount of net sequestrated $\mathrm{C}$ and net $\mathrm{C}$ sequestration potential was

245 significantly affected by soil depth and $\mathrm{N}$ availability, and significant interaction effects were

246 also observed. The amount of net sequestrated $\mathrm{C}$ was significantly higher in surface soil than that

247 in deep soil, but deep soil had significantly higher net $\mathrm{C}$ sequestration potential than surface soil.

$248 \mathrm{~N}$ addition could increase the amount of net sequestrated $\mathrm{C}$ and net $\mathrm{C}$ sequestration potential for

249 both soil depths (Table 2).

250

251

\section{2. $C$ distribution in soil fractions}

252

Glucose addition significantly increased the isotope signature of bulk soil and the seven

253

254

255

256

257

258

259

260

261

262

263

264

265

266

fractions (Fig. 1). Compared to Glu treatment, Glu+N increased the isotope signature of LF, sand, WEOC, and NH-clay fractions in both soil depths, but had no significant effect on bulk soil.

The distributions of the new sequestrated $\mathrm{C}$ in soil fractions were significantly affected by soil depth and $\mathrm{N}$ availability, and interaction effects between soil depth and $\mathrm{N}$ availability were not observed (Table 3 and S2, Fig. 2 and 3). Compared to the deep soil, the new $\mathrm{C}$ in surface soil was more distributed in WEOC (8.5\% VS 5.1\%), LF fraction (6.9\% VS 1.9\%) and silt fraction (58.9\% VS 43.8\%). In contrast, the proportion of new $\mathrm{C}$ associated with clay fraction was higher in deep soil than that in surface soil. When silt and clay fractions were further hydrolyzed by acid, the new $\mathrm{C}$ associated with silt and clay fractions in deep soil was more acid hydrolyzable (91\%) than that in surface soil (80\%). N addition slightly increased the proportion of new $\mathrm{C}$ incorporated into WEOC, sand fraction and NH-clay fraction for both soil depths, whereas showed no significant effects on other fractions. According to the PERMANOVA analysis, the new $\mathrm{C}$ distribution pattern was significantly affected by soil depth $(p=0.0009)$, but not $\mathrm{N}$ addition $(p=0.14)$. 
The seven SOC fractions were grouped into three functional SOC pools for further analysis

268 (Table 4). Compared to deep soil, the new C in surface soil was more distributed in non-

269

270

271

272

273

274

275

276

277

278

279

280

281

282

283

284

285

286

287

288

289

protected pool (15.8\% VS 8.4\%) and biochemically protected pool (15.5\% VS 7.0\%) and less

distributed in chemically protected C pool (58.8\% VS 74.7\%). N addition significantly increased

the proportion of new $\mathrm{C}$ incorporated into non-protected $\mathrm{C}$ pool and biochemically protected $\mathrm{C}$

pool in deep soil $(p<0.05)$, and increased proportion of the new $\mathrm{C}$ incorporated into

biochemically protected $\mathrm{C}$ pool $(p<0.05)$ in surface soil.

The distribution of the new $\mathrm{C}$ in the seven fractions also differed significantly with native $\mathrm{C}$

for both soil depths (Fig. 2). Compared to the native $\mathrm{C}$, the new $\mathrm{C}$ was more distributed in nonprotected $\mathrm{C}$ pool and chemically protected $\mathrm{C}$ pool, and less distributed in biochemically protected C pool $(p<0.05)$.

\subsection{Soil $q \mathrm{CO}_{2}$}

The $q \mathrm{CO}_{2}$ in deep soil was significantly lower than that in surface soil $(p<0.05)$ (Fig.4). In deep soil, treatments of Glu $+\mathrm{N}$ and Glu had significantly lower $q \mathrm{CO}_{2}$ than control treatment. In surface soil, $q \mathrm{CO}_{2}$ showed no significant difference among the three treatments.

\section{Discussion}

\subsection{The retention of glucose-C}

Labile $\mathrm{C}$ input not only altered the native SOC mineralization, but also resulted in new $\mathrm{C}$ formation and sequestration (Cotrufo et al., 2015; Haddix et al., 2016). Previous studies have demonstrated that added glucose can be completely mineralized and assimilated by microbes within 5-7 days (Coody et al., 1986; Baldock et al., 1989; Lundberg et al., 2001; Zhang et al., 
290

291

292

293

294

295

296

297

298

299

300

301

302

303

304

305

306

307

308

309

310

311

312

2015). First, microbes utilized the glucose for biomass production through the in vivo turnover pathway. Second, the glucose-derived microbial residues and their metabolites could be selectively absorbed by soil minerals, and then incorporated into organo-mineral complexes (Liang et al., 2017). Furthermore, the contents of glucose-derived DOC (extracted by 0.05 mol L-

${ }^{1} \mathrm{~K}_{2} \mathrm{SO}_{4}$ for the fresh soil samples at the end of the 20 days incubation) accounted for $0.07 \%$ $0.13 \%$ and $0.3 \%-0.56 \%$ of the added glucose in surface soil and deep soil, respectively (Fig. S3), which indicated that little free glucose left in the soil. Thus, we considered that the retained glucose-C mostly existed as live MBC, microbial necromass or microbial metabolites (Liang et al., 2017, Wang et al., 2020), and soil microorganisms contributed a great role on the C sequestration, especially for the simple C sources (Wardle 1992, Xu et al., 2013, Liang et al., 2017). Since $80 \%$ of the retained glucose-C could incorporate into soil particles eventually (Griepentrog et al., 2014), the retained glucose-C in the soil was considered as new sequestrated $\mathrm{C}$ at the end of incubation.

Our results suggested that deep soil could retain more proportion of exogenous $\mathrm{C}$ than surface soil, which supports our first hypothesis. This could be explained by microbial C use efficiency. $q \mathrm{CO}_{2}$ has been used as a proxy of microbial $\mathrm{C}$ use efficiency. The lower $q \mathrm{CO}_{2}$ values in deep soil (Fig. 3) corresponded to higher $\mathrm{C}$ allocation to $\mathrm{MBC}$ than to respiration losses, indicating a higher $\mathrm{C}$ sequestration potential for glucose- $\mathrm{C}$ (Chen et al., 2018). Previous studies also showed that the $q \mathrm{CO}_{2}$ decreased with soil depth in forest soils (Spohn and Chodak 2015). However, Spohn et al. (2016) suggested that CUE varied little with soil depth in two forests. The discrepancy may be explained by the $\mathrm{C}$ and $\mathrm{N}$ availability or the differences in $\mathrm{MBC}$ and community composition (Spohn and Chodak 2015). Additionally, SOC in deep soil was further away from $\mathrm{C}$ saturation than that in surface soil. According to the conceptual model of $\mathrm{C}$ 
313 saturation, the C-poor deep soil would probably have greater potential and efficiency to retain

314 exogenous C (Stewart et al., 2008; Poirier et al., 2013).

$315 \quad \mathrm{~N}$ addition showed no effect on the amount of retained glucose-C, which was contrary to 316 our second hypothesis. It was likely that $\mathrm{N}$ addition did not significantly affect the microbial $\mathrm{C}$ 317 use efficiency, then did not change the proportion of new $\mathrm{C}$ sequestration. This result concurred 318 with the report that $\mathrm{N}$ addition did not affect the amount of litter-derived SOC in soil, and 319 suggested that the high $\mathrm{N}$ availability in agroecosystem might not affect the $\mathrm{C}$ sequestration 320 (Gentile et al., 2011).

\subsection{The stabilization of new sequestrated $C$}

323 To better evaluate the stabilization of new sequestrated $\mathrm{C}$, we divided the SOC into different fractions. Labile $\mathrm{C}$ addition significantly increased the isotope signature of the soil fractions in both soil depths (Fig. 1), which indicated that glucose-C could be immobilized into all soil fractions. About $80 \%$ of the new $\mathrm{C}$ was associated with silt and clay minerals for both soil depths. This result was in line with other researches, which found exogenous labile $\mathrm{C}$ could be utilized by microorganisms and transformed into mineral-stabilized $\mathrm{C}$ as microbial necromass quickly (Bird et al., 2008; Liang et al., 2017; Garten \& Wullschleger, 2000). Cotrufo et al. (2015) also suggested that $68 \%$ of the litter-derived $\mathrm{C}$ in soil was recovered in the mineral-associated silt and clay fraction in the early stage of litter decomposition. Additionally, there was 5-8\% of the new sequestrated $\mathrm{C}$ distributed in WEOC. The new $\mathrm{C}$ in WEOC was thought to be the labile $\mathrm{C}$ pool and could be mineralized in the foreseeable future. Overall, associated with soil silt and clay minerals were the main stabilization process for the new $\mathrm{C}$.

Soil depths had a significant effect on the distribution of new $\mathrm{C}$ in soil fractions (Fig. 2, 
336 Table 3 and S2). Compared to surface soil, a higher proportion of new $\mathrm{C}$ was stabilized by clay

337 minerals and a lower proportion of new $\mathrm{C}$ were stabilized by silt minerals in the deep soil. This

338 could be explained by a higher proportion of clay particles and a lower proportion of silt particles

339 in the deep soil. New C in surface soil was more distributed in NH-silt (11.1\% VS 3.7\%) and

$340 \mathrm{NH}$-clay (4.9\% VS 3.3\%) than that in deep soil, which may be attributed to the different

341 microbial products and mineralogy composition in different soil depths (Kögel-Knabner, 2002;

342 Silveira et al., 2008; Kallenbach et al., 2016). Thus, the distribution of new C might partly

343 depend on the soil properties.

344 Although $\mathrm{N}$ addition had no effect on the total amount of glucose-C retained in soil, $\mathrm{N}$

345 addition could slightly increase the incorporation of glucose-C into WEOC and sand fraction.

346 The higher distribution of glucose-C in WEOC and coarse fractions under $\mathrm{N}$ addition were also

347 reported by Griepentrog et al. (2014) and Hagedorn et al. (2003). The decreased turnover of

348 these non-protected fractions under $\mathrm{N}$ addition may be responsible for the results (Gentile et al.,

349 2011). $\mathrm{N}$ addition could increase the N-rich microbial products which could be preferentially

350 associated with the organo-mineral complexes rather than directly attached to the mineral surface

351 (Kopittke et al., 2018). This could explain the higher non-hydrolyzable fraction in clay fractions

352 under $\mathrm{N}$ addition in both soil depths.

353 In this study, we divided the SOC into three functional $\mathrm{C}$ pools, namely non-protected C

354 pool, chemically protected $\mathrm{C}$ pool and biochemically protected $\mathrm{C}$ pool. The non-protected $\mathrm{C}$ pool

355 was not stable and could be easily mineralized (von Lützow et al., 2007; Battin et al., 2009;

356 Kindler et al., 2011). Chemically protected C (H-silt and H-clay) is protected by association with

357 mineral particles, where biochemically protected $\mathrm{C}$ is a non-hydrolyzable fraction that is

358 stabilized by its inherent complex biochemical resistance through condensation and 
359 complexation reactions (Six et al., 2002). Nearly $70 \%$ of the new C distributed in chemically

360 protected pool revealed that chemical protection contributes most to $\mathrm{C}$ stabilization. Compared to

361 surface soil, more new C distributed in clay fraction and less new C distributed in non-protected

362 C pool for deep soil suggested that new $\mathrm{C}$ in deep soil was more stable than that in surface soil,

363 which supports our first hypothesis. This result was consistent with previous studies that SOC in

364 deep soil was more stable due to its microbial origin and intimate association with minerals

365 (Rumpel \& Kögel-Knabner, 2011). Although $\mathrm{N}$ addition increased the distribution of new $\mathrm{C}$ in

366 non-protected $\mathrm{C}$ pool and biochemically protected $\mathrm{C}$ pool, PERMANOVA analysis indicated $\mathrm{N}$

367 addition had little effect on the overall new $\mathrm{C}$ distribution pattern (Fig. 2). This result suggested

368 that the effect of $\mathrm{N}$ addition on the new $\mathrm{C}$ stability was limited in the short term.

369 Compared to the native $\mathrm{C}$ for both soil depths, the new $\mathrm{C}$ was distributed more in non-

370 protected $\mathrm{C}$ pool and less in biochemically protected $\mathrm{C}$ pool, indicating that the new $\mathrm{C}$ may be

371 less stable than native C. This result was consistent with previous studies that the new

372 incorporated C were more decomposable than native SOC (Derrien et al., 2014; van Groenigen

373 et al., 2017). Solid-state nuclear magnetic resonance (NMR) spectroscopy analysis also showed

374 that the glucose-C was transformed mostly into O-alkyl $\mathrm{C}$ with little into aromatic $\mathrm{C}$ (Baldock et

375 al., 1989). Low stability of new $\mathrm{C}$ in soil may overestimate the potential of exogenous $\mathrm{C}$

376 sequestration in the short-term. It's notable that we here added the simple decomposable glucose

377 into soil, the proportion of exogenous $\mathrm{C}$ retained and its incorporation into SOC fractions might

378 be different from the complex substrates (e.g. litter and root).

\subsection{The balance between primed $C$ and new $C$}

381 We observed positive PE and new $\mathrm{C}$ sequestration in both soil depths. The effects of labile $\mathrm{C}$ 
382 input on soil C pool should be evaluated in the context of net C sequestration (Qiao et al., 2014).

383 In the present study, both soil depths showed the positive net $\mathrm{C}$ sequestration indicated by the

384 higher amount of new sequestrated $\mathrm{C}$ than the primed $\mathrm{C}$ in bulk soil. The net increase in SOC

385 was about $35 \%$ of the added labile $\mathrm{C}$ which was very similar to the meta-analysis results in Liang

386 et al. (2018). Although deep soil had a relatively higher PE, the net $\mathrm{C}$ sequestration was higher

387 than that in surface soil. In contrast with our results, previous studies showed that SOC pool in

388 deep soil did not increase under the increased exogenous $\mathrm{C}$ input (Mobley et al., 2015). The

389 reasons for these divergent results might be that the quantity and quality of the exogenous $\mathrm{C}$ and

390 soil type were different. Recent studies had demonstrated that when exogenous C was low, the

391 SOC replenishment from exogenous $\mathrm{C}$ could not compensate for the loss of native SOC (Xu er

392 al., 2019). Notably, the amount of added glucose-C in this study was different between the two

393 soils (corresponding $100 \%$ of soil MBC). When the same amount of glucose was added, the

394 pattern of $\mathrm{C}$ sequestration potential between surface soil and deep soil would change and depend

395 on the amounts of added substrates. Thus, the wide application of these results should be

396 cautious. Future studies with more soil types are needed to investigate the effect of quantity and

397 quality of the exogenous $\mathrm{C}$ on net $\mathrm{C}$ balance.

$398 \quad \mathrm{~N}$ addition could enhance positive net $\mathrm{C}$ sequestration through decreasing SOC

399 mineralization (Table 2). The declined PE under $\mathrm{N}$ addition could be explained by "microbial

400 nitrogen mining" hypothesis which assumes that an increase in $\mathrm{N}$ availability will reduce

401 microbial activity in mining SOC (N-containing substrates in soil) to meet $\mathrm{N}$ requirement (Fang

402 et al., 2018, Chang et al., 2019). The significant interaction effect of $\mathrm{N}$ and soil depth suggested

403 that the surface soil tended to retain more net $\mathrm{C}$ under $\mathrm{N}$ addition. This result demonstrated that

404 future $\mathrm{N}$ deposition may favor soil $\mathrm{C}$ sequestration by reducing recalcitrant SOC degradation. 
Our study suggested that deep soil had higher $\mathrm{C}$ sequestration potential than surface soil and

$406 \mathrm{~N}$ addition could improve the net $\mathrm{C}$ sequestration, but widely extrapolating of these results

407 should be cautious. First, all soil samples were sieved through a $2 \mathrm{~mm}$ sieve, which might

408 liberate some physical protected SOC and increase their accessibility to the microbes. The

409 changed soil environments might obscure the results. Second, the 20-day incubation could not

410 represent the long-term soil $\mathrm{C}$ cycling process. Long-term experiments were needed to monitor

411 the processes of $\mathrm{C}$ sequestration. Third, new $\mathrm{C}$ sequestration also varied with the quality and

412 quantity of the exogenous $\mathrm{C}$. Four, compared to $\mathrm{N}$ availability, $\mathrm{P}$ availability was suggested to be

413 more important to soil C cycling in tropical and subtropical forests (Hui et al. 2019). The

414 ignoring of P availability and CNP stoichiometry in this study would constrain the application of

415 our results. Extending studies considering these multiple factors could improve our

416 understanding on $\mathrm{C}$ sequestration potential for subtropical forest soils.

418 5. Conclusion

419 In summary, labile $\mathrm{C}$ addition could result in positive PE in both soil depths, leading to a 420 loss of native SOC. Additionally, labile C input could be sequestrated in soil and

421 overcompensated the C loss induced by PE. Deep soil could sequestrate more proportion of 422 added glucose- $\mathrm{C}$ than surface soil, resulting in greater net $\mathrm{C}$ sequestration. $\mathrm{N}$ addition further 423 increased the positive net $\mathrm{C}$ sequestration by decreasing native $\mathrm{C}$ mineralization rather than 424 through increasing glucose- $\mathrm{C}$ retention. The $\mathrm{C}$ distribution in soil fractions suggested that the 425 new $\mathrm{C}$ in deep soil was more stable than that in surface soil, and the new $\mathrm{C}$ was less stable than 426 the native SOC. Deep soil could retain more proportion of exogenous C with higher stability, 427 suggesting that the deep soil could play a greater role on the $\mathrm{C}$ sequestration and stabilization. 
428 The lower stability of the new $\mathrm{C}$ suggested the soil sequestration potential for exogenous $\mathrm{C}$ could 429 be overestimated in short term studies. Future studies with long-term lab incubations and field 430 studies are needed to explore the controlling factors that mediate net $\mathrm{C}$ balance and new $\mathrm{C}$ 431 stability.

432

433

434

435

436

437

438

439

440

441

442

443

444

445

446

447

448

449

450

\section{Acknowledgments}

This research was supported by the Natural Science Foundation of China (31870465, $31600377,31700462)$.

\section{Reference}

Baldock JA, Oades JM, Vassallo AM, Wilson MA (1989) Incorporation of uniformly labeled 13C glucose carbon into the organic fraction of a soil - carbon balance and CP MAS 13C NMR Measurements. Aust J Soil Res 27:725-746. https://doi.org/10.1071/SR9890725

Battin TJ, Luyssaert S, Kaplan LA, Aufdenkampe AK, Richter A, Tranvik LJ (2009) The boundless carbon cycle. Nat Geosci 2:598. https://doi.org/10.1038/ngeo618

Bird JA, Kleber M, Torn MS (2008) 13C and 15N stabilization dynamics in soil organic matter fractions during needle and fine root decomposition. Org Geochem 39:465-477. https://doi.org/10.1016/j.orggeochem.2007.12.003

Blagodatskaya EV, Blagodatsky SA, Anderson TH, Kuzyakov Y (2007) Priming effects in Chernozem induced by glucose and $\mathrm{N}$ in relation to microbial growth strategies. Appl Soil Ecol 37:95-105. https://doi.org/10.1016/j.apsoil.2007.05.002

Blagodatskaya E, Yuyukina T, Blagodatsky S, Kuzyakov Y (2011) Three-source-partitioning of microbial biomass and of $\mathrm{CO} 2$ efflux from soil to evaluate mechanisms of priming 
451

452

453

454

455

456

457

458

459

460

461

462

463

464

465

466

467

468

469

470

471

472

473

effects. Soil Biol Biochem 43:778-786. https://doi.org/10.1016/j.soilbio.2010.12.011

Blagodatskaya E, Kuzyakov Y (2008) Mechanisms of real and apparent priming effects and their dependence on soil microbial biomass and community structure: critical review. Biol Fert Soils 45:115-131. https://doi.org/10.1007/s00374-008-0334-y

Chang RY, Zhou WJ, Fang YT, Bing HJ, Sun XY, Wang GX (2019) Anthropogenic nitrogen deposition increases soil carbon by enhancing new carbon of the soil aggregate formation. J Geophys Res-Biogeosci 124:572-584. https://doi.org/10.1029/2018JG004877

Chen LY, Liu L, Mao C, Qin SQ, Wang J, Liu FT, Blagodatsky S, Yang GB, Zhang QW, Zhang DY, Yu JC, Yang YH (2018) Nitrogen availability regulates topsoil carbon dynamics after permafrost thaw by altering microbial metabolic efficiency. Nat Commun 9:3951. https://doi.org/10.1038/s41467-018-06232-y

Chen LY, Liu L, Qin SQ, Yang GB, Fang K, Zhu B, Kuzyakov Y, Chen PD, Xu YP, Yang YH (2019) Regulation of priming effect by soil organic matter stability over a broad geographic scale. Nat Commun 10:5112. https://doi.org/10.1038/s41467-019-13119-z

Chen RR, Senbayram M, Blagodatsky S, Myachina O, Dittert K, Lin XG, Blagodatskaya E, Kuzyakov Y (2014) Soil C and N availability determine the priming effect: microbial N mining and stoichiometric decomposition theories. Glob Chang Biol 20:2356-2367. https://doi.org/10.1111/gcb.12475

Cheng WX, Parton WJ, Gonzalez-Meler MA, Phillips R, Asao S, McNickle GG, Brzostek E, Jastrow JD (2014) Synthesis and modeling perspectives of rhizosphere priming. New Phytol 201:31-44. https://doi.org/10.1111/nph.12440

Christensen BT. 1992. Physical fractionation of soil and organic matter in primary particle-size and density separates. In: Stewart, B.A. (Ed.). Advances in Soil Science, vol. 20. Springer, 
New York, pp. 1-90.

475 Christensen BT (2001) Physical fractionation of soil and structural and functional complexity in organic matter turnover. Eur J Soil Sci 52:345-353. https://doi.org/10.1046/j.13652389.2001.00417.x

478

479

480

481

482

483

484

485

486

487

488

489

490

491

492

493

494

495

496

Soil Biol Biochem 18:283-289. https://doi.org/10.1016/0038-0717(86)90062-3

Cotrufo MF, Soong JL, Horton AJ, Campbell EE, Haddix M, Wall DH, Parton WJ (2015)

Formation of soil organic matter via biochemical and physical pathways of litter mass loss. Nat Geosci 8:776-779. https://doi.org/10.1038/ngeo2520

Cotrufo MF, Wallenstein MD, Boot CM, Denef K, Paul E (2013) The Microbial EfficiencyMatrix Stabilization (MEMS) framework integrates plant litter decomposition with soil organic matter stabilization: do labile plant inputs form stable soil organic matter? Glob Chang Biol 19:988-995. https://doi.org/10.1111/gcb.12113

Denef K, Galdo ID, Venturi A, Cotrufo MF (2013) Assessment of soil C and N stocks and fractions across 11 European soils under varying land uses. Open J Soil Sci 3:297. http://dx.doi.org/10.4236/ojss.2013.37035

Derrien D, Plain C, Courty PE, Gelhaye L, Moerdijk-Poortvliet TCW, Thomas F, Versini A, Zeller B, Koutika, Boschker LTS, Epron D (2014) Does the addition of labile substrate destabilise old soil organic matter? Soil Biol Biochem 76:149-160. https://doi.org/10.1016/j.soilbio.2014.04.030

Fang YY, Nazaries L, Singh BK, Singh BP (2018) Microbial mechanisms of carbon priming effects revealed during the interaction of crop residue and nutrient inputs in contrasting soils. Glob Chang Biol 24:2775-2790. https://doi.org/10.1111/gcb.14154 
497 Fontaine S, Barot S, Barre P, Bdioui N, Mary B, Rumpel C (2007) Stability of organic carbon in 498 deep soil layers controlled by fresh carbon supply. Nature 450:277-280.

499 https://doi.org/10.1038/nature06275

500 Garcia-Pausas J, Paterson E (2011) Microbial community abundance and structure are 501 determinants of soil organic matter mineralisation in the presence of labile carbon. Soil $502 \quad$ Biol Biochem 43:1705-1713. https://doi.org/10.1016/j.soilbio.2011.04.016

503 Garten CT, Wullschleger SD (2000) Soil carbon dynamics beneath Switchgrass as indicated by $504 \quad$ stable isotope analysis. J Environ Qual 29:645-653.

505 https://doi:10.2134/jeq2000.00472425002900020036x

506

507

508

509

510

511

512

513

Gentile R, Vanlauwe B, Six J (2011) Litter quality impacts short-but not long-term soil carbon dynamics in soil aggregate fractions. Ecol Appl 21:695-703. https://doi.org/10.1890/092325.1

Griepentrog M, Bode S, Boeckx P, Hagedorn F, Heim A, Schmidt MW (2014) Nitrogen deposition promotes the production of new fungal residues but retards the decomposition of old residues in forest soil fractions. Glob Chang Biol 20:327-340. https://doi.org/10.1111/gcb.12374

Haddix ML, Paul EA, Cotrufo MF (2016) Dual, differential isotope labeling shows the preferential movement of labile plant constituents into mineral-bonded soil organic matter. Glob Chang Biol 22:2301-2312. https://doi.org/10.1111/gcb.13237

Hagedorn F, Spinnler D, Siegwolight R (2003) Increased N deposition retards mineralization of old soil organic matter. Soil Biol Biochem 35:1683-1692. https://doi.org/10.1016/j.soilbio.2003.08.015

Hui D, Porter W, Phillips JR, Aidar MPM, Lebreux SJ, Schadt CW, Mayes MA (2019) 
520

521

522

523

524

525

526

527

528

529

530

531

532

533

534

535

536

537

538

539

540

541

542

Phosphorus rather than nitrogen enhances $\mathrm{CO}_{2}$ emissions in tropical forest soils:

Evidence from a laboratory incubation study. Eur J Soil Sci.

https://doi.org/10.1111/ejss. 12885

Janzen, HH (2015) Beyond carbon sequestration: soil as conduit of solar energy. Eur J Soil Sci 66:19-32. https://doi.org/10.1111/ejss. 12194

Kallenbach CM, Frey SD, Grandy AS (2016) Direct evidence for microbial-derived soil organic matter formation and its ecophysiological controls. Nat Commun 7:13630. https://doi.org/10.1038/ncomms13630

Kindler R, Siemens JAN, Kaiser K, Walmsley DC, Bernhofer C, Buchmann N, Cellier P, Eugste W r, Gleixner G, GrŨNwald T, Heim A, Ibrom A, Jones SK, Jones M, Klumpp K, Kutsch W, Larsen KS, Lehuger S, Loubet B, McKenzie R, Moors E, Osborne B, Pilegaard KIM, Rebmann C, Saunders M, Schmidt MWI, Schrumpf M, Seyfferth J, Skiba UTE, Soussana JF, Sutton MA, Tefs C, Vowinckel B, Zeeman MJ, Kaupenjohann M (2011) Dissolved carbon leaching from soil is a crucial component of the net ecosystem carbon balance. Glob Chang Biol 17:1167-1185. https://doi.org/10.1111/j.13652486.2010.02282.x

Kögel-Knabner I (2002) The macromolecular organic composition of plant and microbial residues as inputs to soil organic matter. Soil Biol Biochem 34:139-162. https://doi.org/10.1016/S0038-0717(01)00158-4

Kopittke PM, Hernandez-Soriano MC, Dalal RC, Finn D, Menzies NW, Hoeschen C, Mueller CW (2018) Nitrogen-rich microbial products provide new organo-mineral associations for the stabilization of soil organic matter. Glob Chang Biol 24:1762-1770.

https://doi.org/10.1111/gcb.14009 
543 Kuzyakov Y (2010) Priming effects: interactions between living and dead organic matter. Soil

544 Biol Biochem 42:1363-1371. https://doi.org/10.1016/j.soilbio.2010.04.003

545 Li QR, Tian YQ, Zhang XY, Xu XL, Wang HM, Kuzyakov Y (2017) Labile carbon and nitrogen

546 additions affect soil organic matter decomposition more strongly than temperature. Appl

547 Soil Ecol 114:152-160. https://doi.org/10.1016/j.apsoil.2017.01.009

548

549

550

551

552

553

554

555

556

557

558

559

560

561

562

563

564

565

Liang C, Balser TC (2012) Warming and nitrogen deposition lessen microbial residue contribution to soil carbon pool. Nat Commun 3:1222. https://doi.org/10.1038/ncomms2224

Liang C, Schimel JP, Jastrow JD (2017) The importance of anabolism in microbial control over soil carbon storage. Nat Microbiol 2:17105. https://doi.org/10.1038/nmicrobiol.2017.105

Liang JY, Zhou ZH, Huo CF, Shi Z, Cole JR, Huang L, Konstantinidis KT, Li XM, Liu B, Luo ZK, Penton CR, Schuur EAG, J. Tiedje M, Wang YP, Wu LY, Xia JY, Zhou JZ, Luo YQ (2018) More replenishment than priming loss of soil organic carbon with additional carbon input. Nat Commun 9:3175. https://doi.org/10.1038/s41467-018-05667-7

Liu S., Zhang ZB, Li DM, Hallett PD, Zhang GL, Peng XH (2019) Temporal dynamics and vertical distribution of newly-derived carbon from a $\mathrm{C} 3 / \mathrm{C} 4$ conversion in an Ultisol after 30-yr fertilization. Geoderma 337:1077-1085. https://doi.org/10.1016/j.geoderma.2018.11.021

Lundberg P, Ekblad A, Nilsso M ( 2001) 13C NMR spectroscopy studies of forest soil microbial activity: glucose uptake and fatty acid biosynthesis. Soil Biol Biochem 33:621-632. https://doi.org/10.1016/S0038-0717(00)00206-6

Midwood AJ, Gebbing T, Wendler R, Sommerkorn M, Hunt JE, Millard P (2006) Collection and storage of $\mathrm{CO} 2$ for 13C analysis: An application to separate soil $\mathrm{CO} 2$ efflux into root- 
566

567

568

569

570

571

572

573

574

575

576

577

578

579

580

581

582

583

584

585

586

587

588

and soil-derived components. Rapid Commun Mass Spectrom 20:3379-3384. https://doi.org/10.1002/rcm.2749

Mobley ML, Lajtha K, Kramer MG, Bacon AR, Heine PR, Richter DD (2015) Surficial gains and subsoil losses of soil carbon and nitrogen during secondary forest development. Glob Chang Biol 21:986-996. https://doi.org/10.1111/gcb.12715

Ohm H, Hamer U, Marschner B (2007) Priming effects in soil size fractions of a podzol Bs horizon after addition of fructose and alanine. Plant Nutr Soil Sci 170:551-559. https://doi.org/10.1002/jpln.200625087

Paul EA (2016) The nature and dynamics of soil organic matter: Plant inputs, microbial transformations, and organic matter stabilization. Soil Biol Biochem 98:109-126. https://doi.org/10.1016/j.soilbio.2016.04.001

Poirier V, Angers DA, Rochette P, Whalen JK (2013) Initial soil organic carbon concentration influences the short-term retention of crop-residue carbon in the fine fraction of a heavy clay soil. Biol Fert Soils 49:527-535. https://doi.org/10.1007/s00374-013-0794-6

Powlson DS, Stirling CM, Jat ML, Gerard BG, Palm CA, Sanchez PA, Cassman KG (2014) Limited potential of no-till agriculture for climate change mitigation. Nat Clim Change 4:678. https://doi.org/10.1038/nclimate2292

Qiao N, Schaefer D, Blagodatskaya E, Zou XM, Xu XL, Kuzyakov Y (2014) Labile carbon retention compensates for $\mathrm{CO} 2$ released by priming in forest soils. Glob Chang Biol 20:1943-1954. https://doi.org/10.1111/gcb.12458

Qiu QY, Wu LF, Ouyang Z, Li BB, Xu YY, Wu SS, Gregorich EG (2016) Priming effect of maize residue and urea $\mathrm{N}$ on soil organic matter changes with time. Appl Soil Ecol 100:65-74. https://doi.org/10.1016/j.apsoil.2015.11.016

Peer] reviewing PDF | (2020:01:45381:1:2:NEW 26 Mar 2020) 
589 Rumpel C, Kögel-Knabner I (2011) Deep soil organic matter-a key but poorly understood

590

591

592

593

594

595

596

597

598

599

600

601

602

603

604

605

606

607

608

609

610

611 component of terrestrial C cycle. Plant soil 338:143-158. https://doi.org/10.1007/s11104010-0391-5

Silveira ML, Comerford NB, Reddy KR, Cooper WT, El-Rifai H (2008) Characterization of soil organic carbon pools by acid hydrolysis. Geoderma 144:405-414. https://doi.org/10.1016/j.geoderma.2008.01.002

Six J, Conant RT, Paul EA, Paustian K (2002) Stabilization mechanisms of soil organic matter: Implications for C-saturation of soils. Review. Plant Soil 241:155-176. https://doi.org/10.1023/A:1016125726789

Spohn M, Chodak M (2015) Microbial respiration per unit biomass increases with carbon-tonutrient ratios in forest soils. Soil Biol Biochem 81:128-133. https://doi.org/10.1016/j.soilbio.2014.11.008

Spohn M, Klaus K, Wanek W, Richter A (2016) Microbial carbon use efficiency and biomass turnover times depending on soil depth - Implications for carbon cycling. Soil Biol Biochem 96:74-81. https://doi.org/10.1016/j.soilbio.2016.01.016

Stewart CE, PaustianK, Conant RT, Plante AF, Six J (2008) Soil carbon saturation: Evaluation and corroboration by long-term incubations. Soil Biol Biochem 40:1741-1750. https://doi.org/10.1016/j.soilbio.2008.02.014

Tian QX, Yang XL, Wang XG, Liao C, Li QX, Wang M, Wu Y, Liu F (2016) Microbial community mediated response of organic carbon mineralization to labile carbon and nitrogen addition in topsoil and subsoil. Biogeochemistry 128:125-139. https://doi.org/10.1007/s10533-016-0198-4

Vance ED, Brookes, PC, Jenkinson DS (1987) An extraction method for measuring soil 
612

613

614

615

616

617

618

619

620

621

622

623

624

625

626

627

628

629

630

631

632

633

634

microbial biomass C. Soil Biol Biochem 19:703-707. https://doi.org/10.1016/00380717(87)90052-6

van Groenigen KJ, Osenberg CW, Terrer C, Carrillo Y, Dijkstra FA, Heath J, Nie M, Pendall E, Phillips RP, Hungate BA (2017) Faster turnover of new soil carbon inputs under increased atmospheric CO2. Glob Chang Biol 23:4420-4429. https://doi.org/10.1111/gcb.13752

von Lützow M, Kögel-Knabner I, Ekschmitt K, Flessa H, Guggenberger G, Matzner E, Marschner B (2007) SOC fractionation methods: relevance to functional pools and to stabilization mechanisms. Soil Biol Biochem 39:2183-2207. https://doi.org/10.1016/j.soilbio.2007.03.007

Wang C, Wang X, Pei GT, Xia ZW, Peng B, Sun LF, Wang J, Gao DC, Chen SD, Liu DW, Dai WW, Jiang P, Fang YT, Liang C, Wu NP, Bai E (2020) Stabilization of microbial residues in soil organic matter after two years of decomposition. Soil Biol Biochem 141:107687. https://doi.org/10.1016/j.soilbio.2019.107687

Wang QK, Wang SL, He TX, Liu L, Wu JB (2014a) Response of organic carbon mineralization and microbial community to leaf litter and nutrient additions in subtropical forest soils. Soil Biol Biochem 71:13-20. https://doi.org/10.1016/j.soilbio.2014.01.004

Wang QK, Wang YP, Wang SL, He TX, Liu L (2014b) Fresh carbon and nitrogen inputs alter organic carbon mineralization and microbial community in forest deep soil layers. Soil Biol Biochem 72:145-151. https://doi.org/10.1016/j.soilbio.2014.01.020

Wang QG, Xu YZ, Lu ZJ, Bao DC, Guo YL, Lu JM, Zhang KH, Liu HB, Meng HJ, Qiao XJ, Huang HD, Jiang MX (2014c) Disentangling the effects of topography and space on the distributions of dominant species in a subtropical forest. Chin Sci Bull 59:5113-5122. 
636 Wardle DA (1992) A comparative assessment of factors which influence microbial biomass carbon and nitrogen levels in soil. Biol Rev 67:321-358. https://doi.org/10.1111/j.1469185X.1992.tb00728.x https://doi.org/10.1111/geb.12029

Xu XR, An TT, Zhang JM, Sun ZH, Schaeffer S, Wang J (2019) Transformation and

Xu X, Thornton PE, Post WM (2013) A global analysis of soil microbial biomass carbon, stabilization of straw residue carbon in soil affected by soil types, maize straw addition and fertilized levels of soil. Geoderma 337:622-629. https://doi.org/10.1016/j.geoderma.2018.08.018 addition as investigated by 13C NMR spectroscopy. Soil Biol Biochem 85:137-144. https://doi.org/10.1016/j.soilbio.2015.03.013 
Figure 1

The isotope signatures of bulk SOC and SOC fractions in surface soil (A) and deep soil (B).

Results are means \pm SE $(n=3)$. Different letters indicated a significant difference among the three treatments in the same fraction
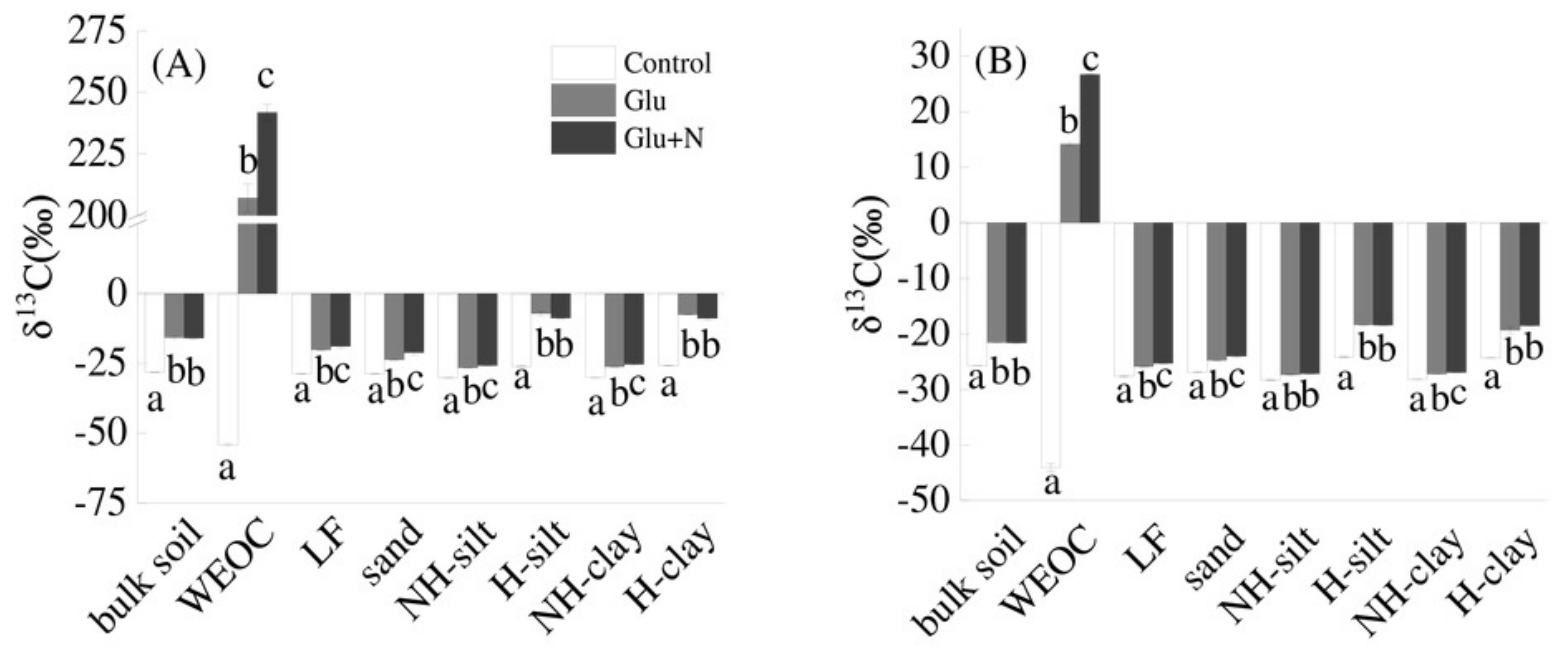
Figure 2

Principal Component Analysis (PCA) of the distribution patterns of new and native $\mathrm{C}$ in surface soil and deep soil.

Square represents the surface soil and circle represents the deep soil. Hollow and black solid denotes new $\mathrm{C}$ under Glu and Glu+N treatments, respectively, and gray solid denotes native C. The results of PERMANOVA show the effects of soil depth and $\mathrm{N}$ addition on the new $\mathrm{C}$ distribution pattern

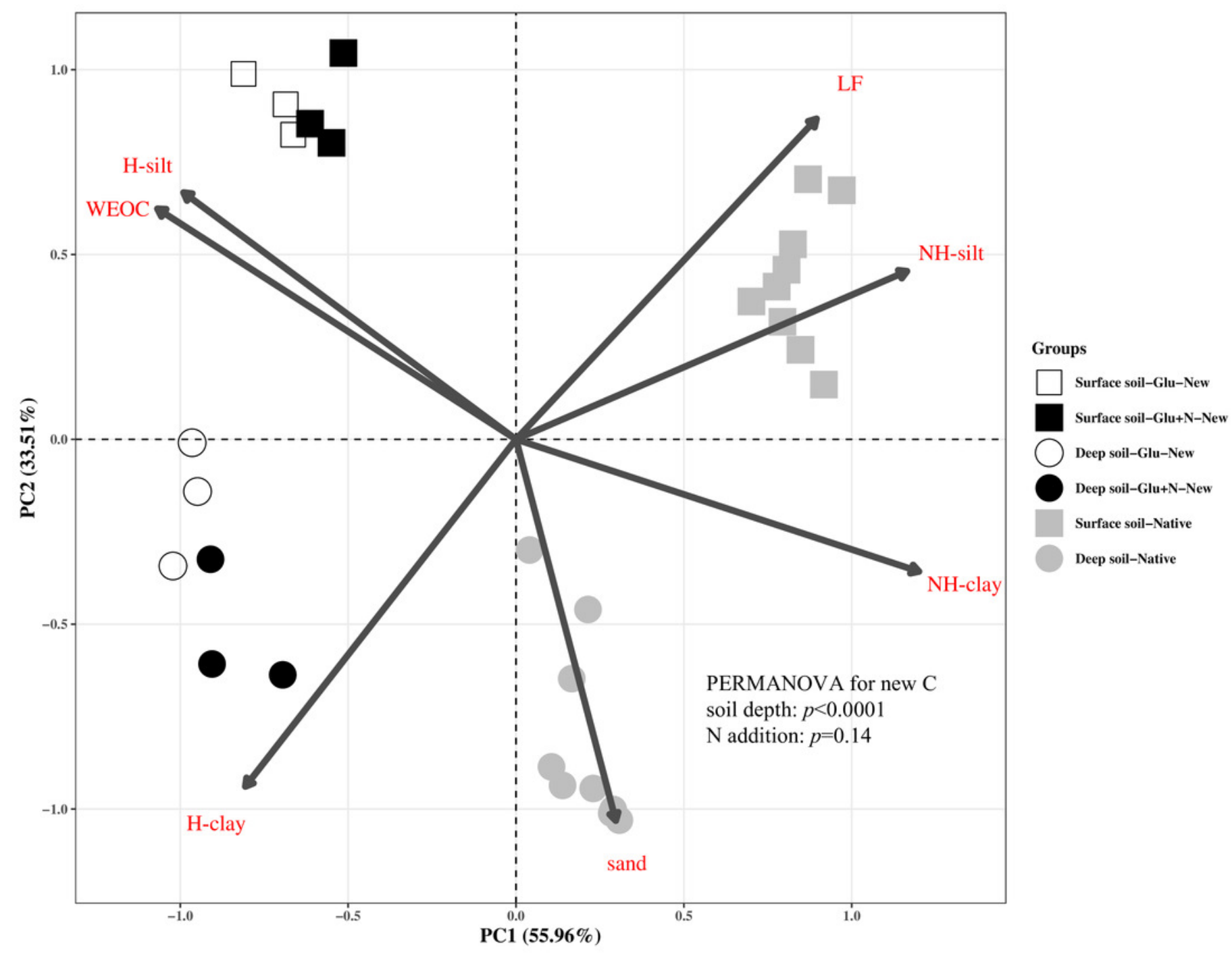


Figure 3

The distribution of new $\mathrm{C}$ in the measured soil fractions after 20 days incubation

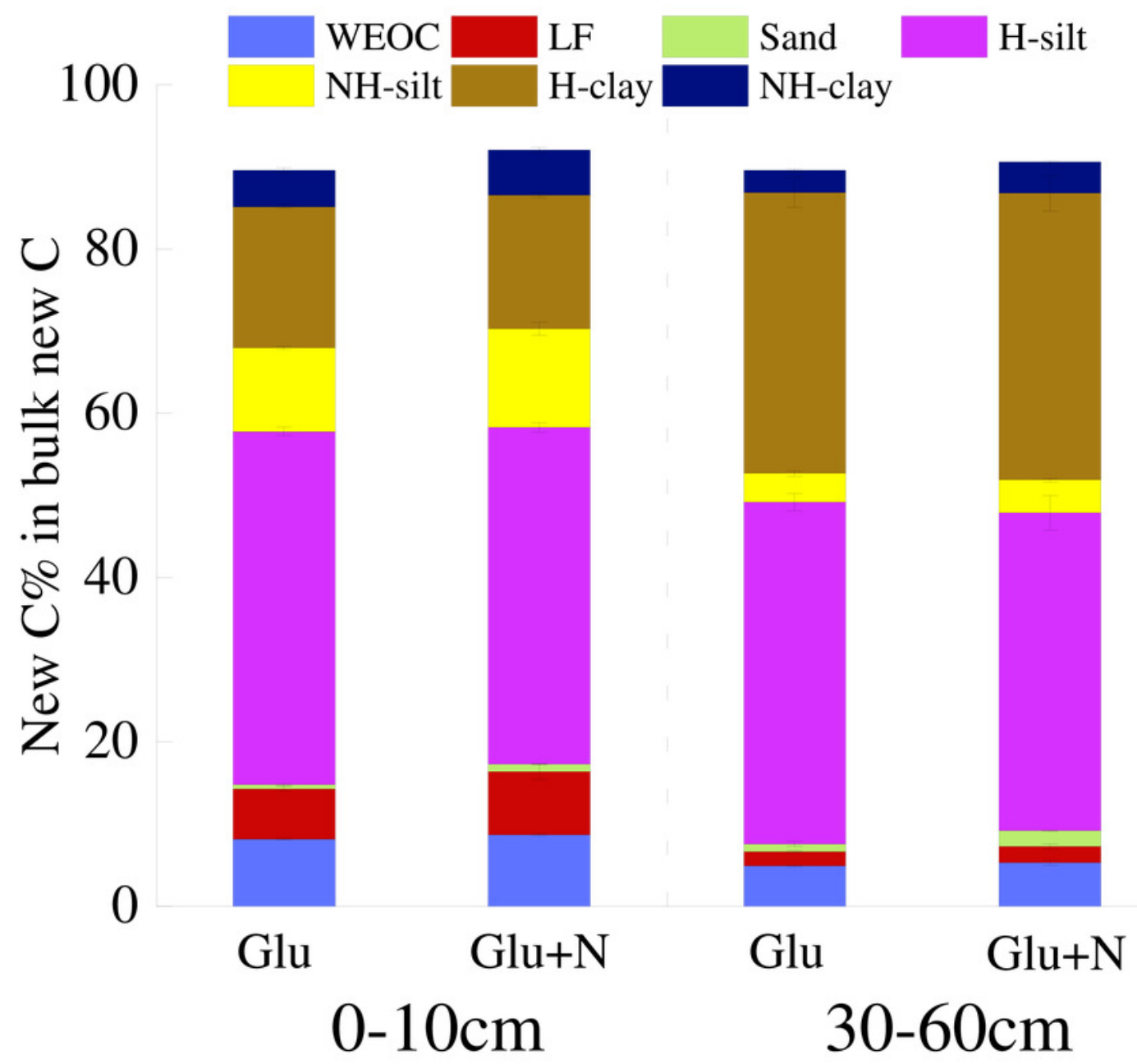




\section{Figure 4}

The effects of glucose and $\mathrm{N}$ addition on $\mathrm{qCO}_{2}$.

The lowercase letter indicated the difference among the different treatments in the same soil depth and capital letters indicated a significant difference between surface soil and deep soil in the same treatment. These values are means $\pm S E(n=3)$
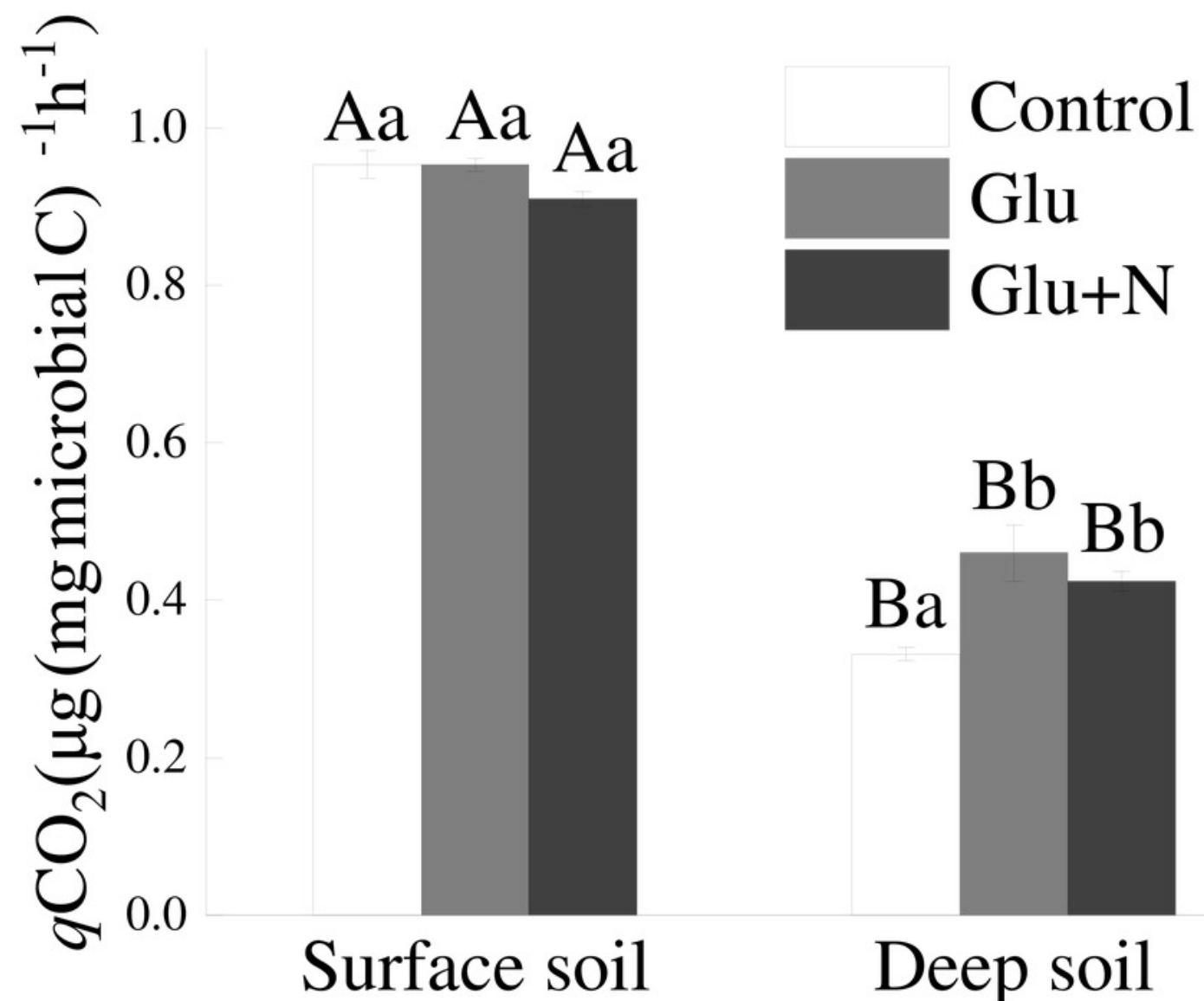


\section{Table $\mathbf{1}$ (on next page)}

Characteristics of the soil samples

Soil microbial biomass C (MBC) was measured after 5 days of pre-incubation. LF\%, sand\%, silt\% and clay\% represented the mass percentage. The WEOC(\%), LF C (\%), sand C (\%), H-silt $\mathrm{C}(\%)$, $\mathrm{NH}$-silt C (\%), H-clay C (\%) and $\mathrm{NH}$-clay C (\%) were the percentage of each fraction $\mathrm{C}$ in total SOC. The mass recovery after fractionation procedure was over $99 \%$. 
1 Table 1 Characteristics of the soil samples

\begin{tabular}{lcc}
\hline Variables & Surface soil $(0-10 \mathrm{~cm})$ & Deep soil $(30-60 \mathrm{~cm})$ \\
\hline SOC $\left(\mathrm{mg} \mathrm{g}^{-1}\right)$ & 131.7 & 35.7 \\
Total N $\left(\mathrm{mg} \mathrm{g}^{-1}\right)$ & 7.9 & 2.7 \\
C/N & 16.7 & 13.4 \\
$\delta^{13}$ C (\%) & -28.2 & -25.8 \\
LF (\%) & 4.04 & 0.56 \\
Sand $(\%)$ & 3.18 & 3.98 \\
Silt (\%) & 70.17 & 55.86 \\
Clay $(\%)$ & 22.61 & 39.60 \\
WEOC $(\%)$ & 0.33 & 0.33 \\
LF C (\%) & 10.14 & 4.11 \\
Sand C $(\%)$ & 0.72 & 2.38 \\
H-silt C $(\%)$ & 28.17 & 33.78 \\
NH-silt C $(\%)$ & 36.58 & 17.11 \\
H-clay C $(\%)$ & 12.03 & 29.11 \\
NH-clay C $(\%)$ & 12.03 & 13.18 \\
MBC $\left(\mu g\right.$ C g ${ }^{-1}$ soil) & 2061.8 & 154.7 \\
\hline
\end{tabular}

2 Soil microbial biomass C (MBC) was measured after 5 days of pre-incubation. LF\%, sand\%, silt \%

3 and clay $\%$ represented the mass percentage. The WEOC (\%), LF C (\%), sand C (\%), H-silt C (\%),

4 NH-silt C (\%), H-clay C (\%) and NH-clay C (\%) were the percentage of each fraction $\mathrm{C}$ in total

5 SOC. The mass recovery after fractionation procedure was over $99 \%$.

6

7 


\section{Table 2 (on next page)}

The amount of primed $\mathrm{C}$, the relative magnitude of $\mathrm{PE}$, the amount of retained glucose $C$, the $C$ sequestration potential and the net $C$ sequestration potential after 20 days incubation

Different capital letters indicate a significant difference between surface soil and deep soil within the same treatment, and different lowercase indicates a significant difference between Glu (single glucose addition) and Glu+N (glucose plus $\mathrm{N}$ addition) within the same soil depth. These values are means \pm SE $(n=3)$. There was no glucose addition in the control treatment, the values were 0 , hence the control treatment was not listed in the table. 
1 Table 2 The amount of primed C, the relative PE, the amount of retained glucose C, the C

2 sequestration potential, the amount of net retained $\mathrm{C}$ and the net $\mathrm{C}$ sequestration potential after

320 days incubation

\begin{tabular}{llllll}
\hline & \multicolumn{2}{l}{ Surface soil } & & Deep soil & \\
\cline { 2 - 3 } \cline { 5 - 6 } Parameters & Glu & Glu $+\mathrm{N}$ & & Glu & Glu $+\mathrm{N}$ \\
\hline Added glucose-C $\left(\mu \mathrm{g} \mathrm{C} \mathrm{g}^{-1}\right.$ soil $)$ & 2061.8 & 2061.8 & & 154.7 & 154.7 \\
Primed C $\left(\mu \mathrm{g} \mathrm{g}^{-1}\right)$ & $257.1 \pm 14.2 \mathrm{Aa}$ & $57.7 \pm 9.5 \mathrm{Ab}$ & & $17.0 \pm 0.3 \mathrm{Ba}$ & $8.9 \pm 0.2 \mathrm{Bb}$ \\
Relative PE $(\%)$ & $28.2 \pm 0.01 \mathrm{Aa}$ & $6.3 \pm 0.01 \mathrm{Ab}$ & & $36.6 \pm 0.0 \mathrm{Ba}$ & $19.1 \pm 0.0 \mathrm{Bb}$ \\
Retained glucose $\mathrm{C}\left(\mu \mathrm{g} \mathrm{g}^{-1}\right)$ & $872.6 \pm 2.5 \mathrm{Aa}$ & $878.0 \pm 2.5 \mathrm{Aa}$ & & $77.2 \pm 1.7 \mathrm{Ba}$ & $79.5 \pm 3.9 \mathrm{Ba}$ \\
The C sequestration potential $(\%)$ & $43.6 \pm 0.1 \mathrm{Aa}$ & $43.9 \pm 0.1 \mathrm{Aa}$ & & $49.9 \pm 1.1 \mathrm{Ba}$ & $51.4 \pm 4.3 \mathrm{Aa}$ \\
The amount of net retained C $\left(\mu \mathrm{g} \mathrm{g}^{-1}\right)$ & $615.5 \pm 14.2 \mathrm{Aa}$ & $820.3 \pm 9.5 \mathrm{Ab}$ & & $60.1 \pm 0.3 \mathrm{Ba}$ & $70.6 \pm 0.2 \mathrm{Bb}$ \\
Net C sequestration potential $(\%)$ & $29.9 \pm 0.7 \mathrm{Aa}$ & $39.8 \pm 0.5 \mathrm{Ab}$ & & $38.9 \pm 0.2 \mathrm{Ba}$ & $45.6 \pm 0.1 \mathrm{Bb}$ \\
\hline
\end{tabular}

4 Different capital letters indicate a significant difference between surface soil and deep soil within

5 the same treatment, and different lowercase indicates a significant difference between Glu

6 (single glucose addition) and Glu+N (glucose plus $\mathrm{N}$ addition) within the same soil depth. These

7 values are means $\pm \operatorname{SE}(n=3)$. There was no glucose addition in the control treatment, the values

8 were 0 , hence the control treatment was not listed in the table. 


\section{Table 3 (on next page)}

The effect of soil depth and $\mathrm{N}$ addition on the new $\mathrm{C}$ distribution in soil fractions

$* p<0.05 ; * * * p<0.001 ;$ ns: not significant. 
1 Table 3 The effect of soil depth and $\mathrm{N}$ addition on the new $\mathrm{C}$ distribution in soil fractions

\begin{tabular}{|c|c|c|c|c|c|c|c|c|c|}
\hline \multirow{2}{*}{$\begin{array}{l}\text { Treatment } \\
\text { effect }\end{array}$} & \multicolumn{5}{|c|}{ Soil fractions } & \multicolumn{4}{|c|}{ silt and clay fractions } \\
\hline & WEOC & LF & sand fraction & silt fraction & clay fraction & H-silt & NH-silt & H-clay & NH-clay \\
\hline Depth & $* * *$ & $* * *$ & $*$ & $* * *$ & $* * *$ & ns & $* * *$ & $* * *$ & $* * *$ \\
\hline Nitrogen & $*$ & ns & $*$ & ns & ns & ns & $*$ & ns & $* * *$ \\
\hline Depth*Nitrogen & ns & ns & ns & ns & ns & ns & ns & ns & ns \\
\hline
\end{tabular}

$2 \quad * p<0.05 ; * * * p<0.001$; ns: not significant. 


\section{Table 4 (on next page)}

The distribution of new $C$ and native $C$ in the three functional SOC pools

For the same functional C pool, different lowercase indicates a significant difference among different treatments within the same soil depth and different capital letters indicate a significant difference for new $\mathrm{C}$ in the same treatment between surface soil and deep soil. * indicated that the incorporation proportion of new $\mathrm{C}$ in the fraction was significantly different with the native $C$. The values for new $C$ are means $\pm S E(n=3)$ and the values for native $C$ are the means \pm SE $(n=9)$ from all treatments. 
1 Table 4 The distribution of new $\mathrm{C}$ and native $\mathrm{C}$ in the three functional SOC pools

\begin{tabular}{|c|c|c|c|c|c|}
\hline \multirow{2}{*}{ SOC pools } & \multirow{2}{*}{ Treatments } & \multicolumn{2}{|c|}{ New $\mathrm{C} \%$ in bulk new $\mathrm{C}$} & \multicolumn{2}{|c|}{ Native $\mathrm{C} \%$ in bulk $\mathrm{C}$} \\
\hline & & Surface soil & Deep soil & Surface soil & Deep soil \\
\hline \multicolumn{6}{|c|}{ Non-protected C pool } \\
\hline & Glu & $14.4 \pm 0.3 \mathrm{Aa}^{*}$ & $7.6 \pm 0.4 \mathrm{Ba}$ & \multirow{2}{*}{$11.8 \pm 0.3$} & \multirow{2}{*}{$6.4 \pm 0.5$} \\
\hline & $\mathrm{Glu}+\mathrm{N}$ & $17.1 \pm 1.1 \mathrm{Aa}^{*}$ & $9.1 \pm 0.3 \mathrm{Bb}$ & & \\
\hline \multicolumn{6}{|c|}{ Chemically protected $C$ pool } \\
\hline & Glu & $60.2 \pm 0.4 \mathrm{Aa}^{*}$ & $75.8 \pm 2.6 \mathrm{Ba}^{*}$ & \multirow{2}{*}{$45.1 \pm 0.9$} & \multirow{2}{*}{$58.1 \pm 1.1$} \\
\hline & $\mathrm{Glu}+\mathrm{N}$ & $57.3 \pm 0.9 \mathrm{Ab}^{*}$ & $73.6 \pm 3.0 \mathrm{Ba}^{*}$ & & \\
\hline \multicolumn{6}{|c|}{ Biochemically protected C pool } \\
\hline & Glu & $14.1 \pm 0.1 \mathrm{Aa}^{*}$ & $6.1 \pm 0.5 \mathrm{Ba}^{*}$ & \multirow{2}{*}{$51.9 \pm 0.7$} & \multirow{2}{*}{$27.3 \pm 0.7$} \\
\hline & $\mathrm{Glu}+\mathrm{N}$ & $16.9 \pm 1.0 \mathrm{Ab}^{*}$ & $7.8 \pm 0.3 \mathrm{Bb}^{*}$ & & \\
\hline
\end{tabular}

2 For the same functional $\mathrm{C}$ pool, different lowercase indicates a significant difference among

3 different treatments within the same soil depth and different capital letters indicate a significant

4 difference for new $\mathrm{C}$ in the same treatment between surface soil and deep soil. * indicated that

5 the incorporation proportion of new $\mathrm{C}$ in the fraction was significantly different with the native

6 C. The values for new $C$ are means $\pm S E(n=3)$ and the values for native $C$ are the means $\pm S E$

$7 \quad(n=9)$ from all treatments. 